\title{
Processamento em leitura, estrategias metacognitivas e ensino: revisitando os temas
}

\author{
Reading processing, metacognitve strategies and teaching: revisiting the themes
}

\section{Rejane Croharé Dania}

\author{
Universidade Estadual do Sudoeste da Bahia - UESB - Bahia - Brasil
}

\begin{abstract}
RESUMO: À luz da psicolinguística, o presente artigo tematiza leitura, processamento em leitura e o ensino de estrategias metacognitivas em contexto escolar brasileiro. Descreve-se pesquisa realizada em escola pública no ano de 2005, na capital de Santa Catarina. Buscou-se indentificar o perfil dos participantes que completavam a oitava serie, por meio de quatro instrumentos: (1) questionário de identificação para coletar nome, data, local de nascimento e se era aluno repetente; (2) levantamento psicossociolinguístico para descobrir hábitos de leitura e escrita dos participantes; (3) pré-teste para avaliar o desempenho em leitura antes da intervenção e (4) pós-teste para avaliar o desempenho após a intervenção. Partiu-se dos resultados de desempenho em leitura do Programa Internacional de Avaliação de Alunos (PISA, 2000) e do Índice de Analfabetismo Funcional (INAF, 2001, 2003 e 2005) que mostram que os brasileiros leem, mas estão limitados a localizar e recuperar informações explícitas. A hipótese alternativa defendida nesta pesquisa é que alunos submetidos a um programa de leitura e uso de estratégias metacognitivas apresentam melhor desempenho em leitura. Os dados empíricos serviram para testar as hipóteses após a análise quantitativa, estatística e qualitativa. Os resultados quantitativos do pós-teste mostraram variabilidade nos escores. O tratamento estatístico dos dados possibilitou afirmar que houve diferença significativa entre o pré e o pós-teste, confirmando a hipótese alternativa desta pesquisa.
\end{abstract}

Palavras-chave: Leitura, processamento em leitura, estratégias metacognitivas.

ABSTRACT: In the light of psycholinguistics, the article investigates reading, reading processing and the use of metacognitive strategies in the Brazilian school context. The research aimed at two groups of the eighth grade of a public school in Florianópolis, SC, Brazil in 2005. In order to carry it out four instruments were applied: (1) the identification questionnaire in order to collect information related to name, place and date of birth and if students had repeatead any grade before; (2) the psycosociolinguistic questionnarie to find out reading and writing habits of the participants; (3) the pre-test to evaluate reading performance before intervention and (4) the post-test to evalute reading performance after intervention. The results of PISA (Programme of International Student Assessment, 2000) and of the INAF (Índice Nacional de Analfabetismo Funcional, 2001, 2003, 2005) served as base for this research and showed that Brazilians read, but are limited to locate and recover explicit information. The alternative hypothesis affirms that students submitted to a programme of devolopment of metacognitive strategies achieve a better reading performance. The data served to test the hypothesis after the quantitative, statistic and qualitative analysis. The quantitative results of the post-test showed that there was variability on the scores. The statistical analysis enabled the confirmation that there was a significative difference between pre and post- tests. It was possible to confirm the alternative hypothesis of this research.

Keywords: Reading, reading processing, metacognitive strategies. 


\section{Introdução}

A leitura de textos de diversos gêneros e em diferentes suportes está presente na vida das sociedades grafocêntricas, isto é, centradas no uso da escrita. Para atender às exigências de compreender textos em prosa, gráficos, tabelas, para citar apenas alguns, o leitor deve estar preparado para melhor participar das demandas sociais tanto na esfera escolar quanto fora dela. Não é isso o que ocorre, pois, o desempenho sofrível em habilidades de leitura localistas de informações é realidade. Os alunos decodificam, mas não compreendem o texto e, consequentemente, não conseguem avançar para habilidades mais complexas de leitura: interpretar as informações, inferir e refletir a partir das informações fornecidas pelo texto configurando a categoria chamada de analfabetos funcionais.

A fim de colher dados empíricos sobre o problema, esta pesquisa investigou os alunos que completaram a oitava série do ensino fundamental brasileiro no ano de 2005 em uma escola pública na cidade de Florianópolis, Santa Catarina, Brasil. A escolha se deveu ao fato de aquela escola ter sido avaliada no ano de 2000 pelo Programa Internacional de Avaliação de Estudantes (PISA, doravante). Foram desenvolvidos quatro instrumentos de pesquisa que procuraram: 1) identificar os alunos; 2) traçar o perfil socioeconômico dos participantes e seus hábitos de leitura e de escrita; 3) avaliar desempenho em leitura antes da intervenção e 4) avaliar o desempenho em leitura pós-intervenção. A hipótese, defendida na pesquisa, foi a de que alunos submetidos a um programa de leitura e de uso de estratégias metacognitivas melhoram seu desempenho em leitura. Os dados coletados após a intervenção participativa nos permitiram afirmar que estatisticamente houve diferença entre o desempenho de leitura entre pré e pós-teste.

Procurou-se compreender a complexidade do processamento em leitura no contexto investigado tanto na dimensão individual quanto na dimensão social, pois ler é um conjunto de habilidades e conhecimentos linguísticos e psicolinguísticos que se extende desde a habilidade de decodificar palavras escritas à capacidade de compreender textos e participar de práticas sociais de leitura. Por seu turno, escrever compreende desde a habilidade de codificar sons até a capacidade de comunicar-se por escrito com alguém, produzindo textos com coerência e coesão, em diversos gêneros adequados aos fins pragmáticos: usos na dimensão social.

A fase inicial de aprendizagem de um sistema de escrita chama-se alfabetização: o domínio das correspondências grafofonológicas e fonológicografêmicas no aspecto instrumental e individual; o exercício voltado para as práticas sociais e consequente desenvolvimento das habilidades de ler e escrever denomina-se letramento (TFOUNI, 1995, p.19).

É importante salientar que o conceito de alfabetizado vem sofrendo mudanças ao longo do tempo: em contexto nacional, o Instituto Brasileiro de Geografia e Estatística (IBGE) considerava, em 1940, o critério de "saber ou não assinar o nome", em 1950, passou a adotar "saber ou não saber ler e escrever um bilhete simples". A década que separa os dois criterios adotados denota um avanço nas habilidades, isto é, de assinar o nome para ler e escrever um bilhete.

Em contexto internacional, a UNESCO, em 1958, definia como alfabetizada a pessoa capaz de ler e escrever um enunciado simples e analfabeta aquela que era incapaz de ler e escrever uma pequena frase sobre o cotidiano. Vinte anos depois, houve uma revisão desta dicotomia e a UNESCO sugeriu o conceito de analfabeto funcional:

"É funcionalmente alfabetizada a pessoa que puder engajar-se em todas as atividades nas quais o letramento for requerido para o efetivo funcionamento de seu grupo e de sua comunidade e também capacitá-lo a continuar usando a leitura, a escrita e cálculo para seu próprio desenvolvimento e 0 de sua comunidade. É funcionalmente analfabeta a pessoa que não puder engajar-se em todas as atividades nas quais o letramento for requerido para o efetivo funcionamento de seu grupo e de sua comunidade e também o for para capacitá-lo a continuar usando a leitura, a escrita e o cálculo para seu próprio desenvolvimento e o de sua comunidade" (UNESCO, 1979, p.183). 
A mudança na definição decorre das transformações sociais e econômicas, porém não podemos voltar à dicotomia analfabeto/alfabetizado e aplicá-la ao analfabeto funcional, pois estamos tratando do que e como as pessoas usam as habilidade de ler e escrever. Em contexto brasileiro, o termo letramento, ao invés de alfabetismo vem sendo usado usado para designar este conceito (RIBEIRO, INAF, 2006) que corresponde a literacy, do inglês, litttératie, do francês e literacia em Portugal. Assumiuse letramento, neste estudo, como estado ou condição das habilidades de leitura e escrita (individual) em uma perspectiva de continuum conforme aponta Soares (2003) e permeado por eventos e práticas (sociais) e mais indiretamente a possibilidade de imbricar estas dimensões com 0 processamento em leitura sob orientação psicolinguística.

Assim colocado, o fenômeno denominado analfabetismo funcional revela lacunas que impossibilitam a pessoa de participar do grupo social de que faz parte, bem como de usar a leitura, escrita e cálculo para as atividades diárias e para seu próprio desenvolvimento que podem ser exemplificadas pelas dificuldades de ler gráficos, tabelas de horarios de ônibus, administrar o uso do talão de cheque e extrato bancário, etc.

O avanço na escolaridade demonstra que as dificuldades de compreender textos sobre temas diversos em áreas distintas de conhecimento se amplificam. As perguntas que incitaram este estudo derivaram de compreender as razões destas dificuldades: o que os estudantes leem? Não compreendem o texto todo ou parte, partes do texto? De que natureza são estas dificuldades?

Com base nestas perguntas, procurou-se mapear o contexto de investigação mencionado por meio dos instrumentos de pesquisa já citados, buscando avaliar o desempenho em leitura dos participantes investigados, dentro do quadro conceitual assumido. Buscou-se apresentar e aplicar técnicas e estratégias metacognitivas de leitura visando criar autoconsciência no leitor sobre a aprendizagem destas habilidades com vistas a melhorar o desempenho em leitura destes participantes.

Este artigo, de orientação psicolinguística, tematiza leitura, descreve a pesquisa realizada, seguido do referencial teórico que revisita 0 processamento em leitura e estratégias de leitura que subsidiam o método procurando explorar os objetivos traçados para este estudo. As seções seguintes, Análise dos Resultados e Discussão Geral, procuram explicar e discutir à luz dos referenciais assumidos, a complexidade do fenômeno estudado. Resulta deste esforço interpretativo as implicações e efeitos para o ensino com vistas a desenvolver monitoramento regular dos padrões de desempenho dos sujeitos que completam o ensino fundamental em contexto escolar brasileiro.

\section{Revisitando os conceitos de leitura, processamento em leitura e estratégias metacognitivas.}

Os primeiros estudos sobre os processos de leitura (JAVAL, 1879 apud MORAIS, 1996) descreviam os aspectos fisiológicos envolvidos, isto é, os movimentos oculares. Os modelos teóricoexplicativos são datados de apenas quatro décadas e esboçam de forma descritiva o percurso do estímulo visual (input) até a compreensão.

Ler escrever são atividades cognitivas, isto é, atividades de processamento da informação, que compartilham com falar e escrever a cadeia da fala o fato de a informação ser de natureza linguística (MORAIS, KOLINSKY, 2004, p.14). Compreender a fala e falar são características biopsicológicas da espécie humana adquiridas na infância e desencadeadas por fatores maturacionais e sociais; ler e escrever demandam instrução.

A leitura, sob o ponto de vista linguístico, demanda um conjunto de habilidades fonológicas, morfológicas, sintáticas, semânticas e pragmáticas que igualmente são compartilhadas com a fala, porém o processo de identificação visual da palavra cabe somente à leitura. É esse input visual que precisa ser traduzido em representação fonológica para que a palavra seja lida. Igualmente, é essa capacidade de 
identificação que permite acessar, através da representação fonológica, o significado da palavra. Este processo é chamado de acesso lexical.

Esta fase somente não permite que o leitor avance no sentido da compreensão do texto. Isto se deve ao fato de a leitura ter e ser de caráter plural, multifacetado que envolve percepção, processamento, memoria, inferência e dedução. Desta forma, a leitura não está limitada à capacidade de decodificação (palavra por palavra) e ser considerada linear (uma linha após a outra).

\subsection{O processamento em leitura}

O processo de decodificação, isto é, o reconhecimento de letras e valores atribuídos aos grafemas, se dá a partir do input visual que, por meio dos movimentos oculares chamados sacadas, possamos deslocar o olhar e fazer a fixação: pausa dos olhos sobre um ponto específico entre duas sacadas. Este movimento possibilita que sejam fatiadas e extraídas as informações que viabilizam o reconhecimento da palavra, identificando-a e construindo seu sentido, passando, então, à palavra seguinte e repetindo 0 processo nas palavras subsequentes até formar uma sentença.

Quando aprendemos a ler, precisamos dominar dois processos que são de natureza sensório-fisiológica e cognitiva: os processos lexicais e os processos de compreensão. Os primeiros envolvem sacadas e fixações usadas para reconhecer letras e palavras, ativando a memória sobre a representação visual da palavra que é emparelhada com aquela internalizada pelo leitor. Scliar-Cabral (1991, p. 45) afirma que "trata-se do reconhecimento de unidades dotadas de significação." Quanto mais rápida for a identificação da palavra, mais memória de trabalho estará disponível às operações sintática, semântica e de integração das frases no texto. Desta forma, o componente seguinte entra em ação: os processos de compreensão utilizados para entender o texto como um todo significativo.

Morais (1996) afirma que o padrão dos movimentos oculares de um mesmo leitor, seja qual for seu nível, varia amplamente segundo o grau de dificuldade do texto. Quando um leitor hábil tem que ler um texto muito difícil, seu padrão de movimentos oculares aproxima-se daquele de um leitor menos hábil. "É o nível de leitura e o grau de dificuldade do texto que determinam os movimentos dos olhos, não o contrário" (op.cit., p. 119).

A impossibilidade de podermos fixar um grande número de palavras em uma única linha devese à perda de acuidade a partir do ponto de fixação. $\mathrm{Na}$ escrita alfabética, podemos identificar a parte do texto que se estende de quatro caracteres à esquerda do ponto de fixação até sete caracteres à direita. Para aprofundamento sobre os sistemas de escrita e os princípios do sistema alfabético do português remeto a Scliar-Cabral (2003 a, b).

Os primeiros estudos sobre os processos de leitura permitiram compreender os aspectos fisiológicos já descritos. As pesquisas psicolinguísticas referentes ao processamento em leitura são mais recentes e refletem uma visão de leitura que privilegia dois polos, isto é, o texto ou o leitor. A partir do ponto de vista que privilegiam derivam classificações dos modelos. Assim colocada, a leitura passa a ser vista como extração de significado, atribuição de significado ou como interação com o texto ocupando posição intermediaria entre os dois polos.

O modelo ascendente de leitura, bottom-up (GOUGH, 1976), tem como ponto focal o texto. Este é um procedimento muito empregado nos processos iniciais de aprendizagem da leitura e igualmente em textos de maior complexidade para o leitor, pois demandam um processamento cuidadoso para que o texto seja compreendido e o sentido de um texto construído.

Ao atribuir sentido às palavras, frases, enunciados o leitor parte dos signos, isto é do particular para o geral, desconsiderando conhecimentos e expectativas. Caracteriza-se por ser um processo linear e indutivo. Se o tema proposto pelo texto não é familiar ao leitor, uma abordagem ascendente deve se realizar, pois desta forma o leitor construirá novos esquemas (organizões de 
informações armazenadas na memoria: para o esquema biblioteca acionaríamos livros, estantes, mesas etc). $\mathrm{O}$ modelo de Gough é bastante representativo, evidenciando processos em seqüência e o modelo de LaBerge e Samuels (1974) é também ascendente e remeto a leitura para maior detalhamento.

É fato que muito tempo é consumido na fase de decodificação, pois é grande o esforço para reconhecer letras restando pouco fôlego para as tarefas de compreender o texto, devido às limitações na memória de trabalho (MORAIS, 1996). Muito tempo e esforços são gastos até que estes procedimentos estejam automatizados e integrados. Porém, à medida que o aprendiz caminha na direção do desenvolvimento destas habilidades, mais recursos são disponibilizados para o processamento e armazenamento que viabilizam a compreensão e construção de sentido de um texto (CARPENTER; MIYAKE; JUST, 1994; GRIMM-CABRAL, 2000).

Por seu turno, no modelo descendente, topdown, o leitor passa a comparar as hipóteses levantadas com as informações apresentadas pelo texto. Assim, vai confirmando ou refutando as hipóteses primeiramente levantadas pelo leitor com o conhecimento apresentado. O modelo proposto por Goodman (1976) caracteriza-se por apresentar os processos de leitura mais ligados aos conteúdos arquivados na memória e à confirmação ou refutação de hipóteses e aos ajustes necessários, portanto, a leitura não mais é vista como um processo linear, mas como um levantamento de hipóteses ligado à adivinhação ou um jogo de adivinhação. Neste processo a compreensão não é um produto final ao término da leitura, mas um processo que se desenrola ao longo da leitura. É por isto que a leitura é caracterizada como descendente, pois se inicia na mente do leitor e chega ao texto. Ao contrário do modelo anteriormente descrito, o ponto de partida para a compreensão são as hipóteses levantadas com base no conhecimento prévio do leitor sobre o tema e na parte do texto já lida. No modelo proposto por Goodman, a leitura é um processo não linear, dinâmico na inter-relação de vários componentes. É uma atividade essencialmente preditiva para a qual o leitor precisa usar seu conhecimento lingüístico, enciclopédico e sua experiência.

Os modelos interativos defendem que a informação contida página e a informação trazida pelo leitor se encontram por meio de uma atividade essencialmente cognitiva. Rumelhart (1977) propõe que a leitura se inicia com o input visual do texto: a informação é analisada por meio da extração de traços e o resultado desta é encaminhado ao sintetizador de padrões, dispositivo que analisa as informações no nível ortográfico, lexical, sintático e semântico. Somente após estas operações, pode-se chegar ao sentido do texto. Nas palavras de Rumelhart "a leitura é o processo de compreensão da linguagem escrita. Começa com um movimento padronizado na retina e termina (quando bem sucedida) com uma idéia definida sobre a mensagem pretendida do autor" (1977, p.864).

Há que destacar os modelos interativocompensatórios que defendem que a compreensão resulta de informações do próprio texto combinadas aos conhecimentos prévios do leitor e apontam que eventuais deficiências em qualquer nível de análise, sintática, semântica, morfológica etc, serão compensadas pelo uso de outras fontes de conhecimento conforme Stanovich (1980) e ScliarCabral (1991).

Stanovich (1980) defende que tanto o mau leitor quanto o leitor iniciante recorrem a pistas sintáticas e semânticas para compensar habilidades pouco proficientes na decodificação. O leitor fluente, dada a habilidade de reconhecer palavras já desenvolvida, não faria uso desta compensação. A hipótese da compensação desenvolvida por Stanovich (1980) defende que a compreensão de um texto envolve várias fontes de conhecimento: lexical, sintático, textual, discursivo, etc. Assim, deficiências em uma destas fontes seriam compensadas por competências em outras. O termo interativo, empregado no modelo, significa a atuação do leitor sobre o texto, promovendo ativação de esquemas (conhecimento prévio) e inferências a partir do texto. 
Alguma falha em processamento é controlada pelo leitor e não pelo texto.

Scliar-Cabral (1991, p.12-141) propõe um modelo integrado, contextual, interativo, dinâmico e criativo de recepção e produção de linguagem. A autora explica que o leitor coloca na memória operacional a fatia de informação retirada do texto. A seguir faz uma segmentação provisória e emparelha esta informação com aquela contida na memória lexical e semântica. Havendo adequação, o processo segue na direção do item seguinte. Desta forma, o leitor se utiliza da decodificação e igualmente da informação contextual e do conhecimento prévio.

Para efeitos de descrição deste estudo, interessa recortar deste modelo o sistema verbal que se subdivide em lecto-escrito e audiovocal. Compõe o sistema lecto-escrito os componentes grafêmico, morfológico, gramatical, textual e lexical ortográfico. Desta forma, a autora defende que ler é um processo receptivo que envolve decodificação,compreensão, interpretação e retenção da informação.

Segundo Scliar-Cabral (1986), a decodificação é responsável pelo reconhecimento dos símbolos escritos e de sua ligação com um significado. Somente esta etapa não garante a leitura, pois é a primeira parte do processo. A compreensão refere-se à captação temática e dos tópicos principais do texto que se lê. São usados os conhecimentos das regras sintáticas e semânticas da língua. É necessário também conhecer as regras textuais e depreender a significação das palavras novas. Ao compreender um texto, o leitor usa seu conhecimento prévio, estabelecendo novas relações com o que está sendo trazido enquanto informação nova. Assim, o leitor amplia sua rede de conhecimentos, reformulando e ampliando seus esquemas anteriores. Ancorada na compreensão, e dela dependente, ocorre a interpretação. É nesta fase que o leitor utiliza a capacidade crítica e faz julgamentos sobre o que lê. Finalizando a descrição, ocorre a retenção que é responsável pelo armazenamento das informações na memória de longo prazo.

Em obras posteriores (SCLIAR-CABRAL, 2003, a,b) a autora acrescentou as etapas pré-leitura e monitoria ao modelo. A pré-leitura "descreve a seleção do esquema mental para nós atribuirmos o sentido adequado às palavras do texto." (op. cit. p.35); já a monitoria "é uma forma de desenvolver a metalinguagem, ou seja se debruçarem reflexivamente sobre o que escreveram." (op.cit, p. 74). A monitoria também se aplica à leitura e significa acompanhar sua própria compreensão em leitura.

\subsection{Estratégias de leitura}

As estratégias de leitura são ações empregadas pelos leitores no ato de ler. Segundo Brown (1980, p. 465) estratégia é "qualquer controle deliberado ou planejado de ações que levam a compreensão"; segundo Oxford (apud Fujita 2001, p. 03) "estratégias são criadas para um objetivo, potencialmente observáveis, potencialmente ensináveis e flexíveis". Segundo a autora, é possível observar o comportamento do leitor (virar a página, acompanhar os movimentos oculares), excluindo-se as ações mentais que só podem ser inferenciadas. No que diz respeito ao "potencialmente ensináveis", a autora se refere à instrução do professor. Goodman (1976) defende que uma estratégia é um amplo esquema para obter, avaliar e utilizar informação. Assim, os leitores desenvolvem estratégias para construir sentido de um texto. Na literatura, as estratégias são classificadas em estratégias cognitivas e estratégias metacognitivas.

\subsubsection{Estratégias cognitivas}

As estratégias automáticas, inconscientes, possibilitam a leitura rápida e eficiente e são chamadas de estratégias cognitivas. Nesta perspectiva, Goodman (1976) arrola três tipos de estratégias de natureza cognitiva: a seleção, a predição e a inferenciação. À seleção cabe a escolha dos itens mais úteis oferecidos pelo texto. A predição utiliza o conhecimento disponibilizado pelo texto para predizer (hipótese) o que virá na seqüência. A predição depende da base de dados previamente selecionados. O leitor não precisa predizer acuradamente todo o texto, mas é desejável que consiga desconsiderar hipóteses absurdas. Segundo 
Smith e Goodman (apud KATO, 1986, p. 10), é a interação entre as pistas visuais e o conhecimento armazenado na memória do leitor que viabiliza a predição.

As inferências são estratégias que o leitor usa para complementar a informação disponibilizada pelo texto. Entram em cena o conhecimento conceitual, o linguístico e os esquemas que o leitor já possui, conforme Goodman (1976). Segundo Scliar-Cabral (1986, p. 77) quanto maior o conhecimento prévio do leitor e o domínio do sistema linguístico, dos esquemas textuais e do tema abordado pelo texto, mais eficientes e ricas serão as inferências desenvolvidas.

Kato (1986) defende que as estratégias cognitivas são automáticas: (1) as estratégias de segmentação sintática e de recuperação anafórica; (2) as estratégias de reconhecimento global de palavras; (3) a utilização do contexto para inferir significado. A autora aponta que estas estratégias (cognitivas) derivam do Princípio da Canonicidade, isto é, ordem natural de nível sintático ou semântico que permite ao leitor fazer inferências, por exemplo, ao se depreender a categoria gramatical de uma palavra desconhecida na leitura, e do Princípio da Coerência que busca a coerência no texto. Este último princípio se traduz por coerência global, coerência local e coerência temática. Para Kato (1986), busca-se na coerência global a intenção do autor; para a coerência local, busca-se a compreensão de uma ou mais partes de um texto, procurando construir sentido; para a coerência temática, a atenção se volta para o tema, o título e o uso destas informações direcionadas para a compreensão do texto.

\subsubsection{Estratégias metacognitivas}

As estratégias metacognitivas são aquelas que orientam 0 comportamento consciente do leitor. Têm a finalidade de resolver equívocos ou dúvidas percebidos após o processamento da fase automática, ou mesmo permitir a desautomatização de estratégias cognitivas buscando o auto-regulamento da compreensão.
Brown (1980, p.453-456) define metacognição como controle consciente e deliberado de ações cognitivas. Um leitor eficiente faz uso de uma variedade de estratégias para garantir a compreensão do texto.

Pelo que já foi exposto, pode-se afirmar que por meios das estratégias cognitivas o leitor consegue ler e compreender o texto com sucesso. Caso o leitor se depare com dificuldades na compreensão, passa a empregar estratégias metacognitivas para sanar esta lacuna. Assim, descobre o que está faltando no texto ou em seu próprio conhecimento internalizado.

Parece não haver consenso na literatura no que diz respeito ao grau de consciência de uso das estratégias metacognitivas: Brown (1980) defende que as ações são intencionalmente selecionadas; Faerch e Kasper (1980) referem-se a ações potencialmente conscientes. Encontram-se abaixo listadas algumas das atividades que Brown (1980) considera de natureza metacognitiva: (a) explicitação dos objetivos de leitura, (b) identificação dos aspectos importantes na mensagem, (c) alocamento de atenção a áreas importantes, (d) monitoração do comportamento para ver se está havendo compreensão, (e) engajamento em revisão para verificar se o objetivo está sendo atingido, (f) tomada de ações corretivas quando são detectadas falhas na compreensão, $(\mathrm{g})$ recuperação da atenção quando a mente se distrai ou faz digressões.

Os estudos mencionados evidenciam que os processos cognitivos são responsáveis pelo comportamento automático do leitor, por seu turno, os processos metacognitivos os desautomatizam e, portanto, demandam monitoria da compreensão realizada pelo leitor durante a leitura. Segundo Baker e Brown (1984a, p. 22), a metacognição, a monitoria e a monitoria da compreensão em leitura estão co-relacionadas. A monitoria é um tipo de monitoria cognitiva e esta é um dos elementos da metacognição. Nesta perspectiva, a metacognição 
se une ao conhecimento de habilidades e estratégias associado à habilidade de usar mecanismos que favoreçam a execução da leitura com compreensão.

Com base no exposto, definir objetivos para a leitura, categorizar e hierarquizar informações ao longo da leitura, identificando aquelas informações que são mais importantes e avaliando sua compreensão são fatores que favorecem o bom desempenho, conforme se verificou neste estudo e será detalhado na discussão dos resultados. É de salientar igualmente a importância de tomar atitude quando ocorrem falhas de compreensão. Para isso, reler e ativar conhecimento prévio são fundamentais. Há que se considerar que as estratégias de leitura variam conforme as características cognitivas e proficiência em leitura de cada leitor.

Nesta seção, apresentou-se 0 processamento em leitura, revisando modelos e descrevendo o modelo Scliar-Cabral (1991) adotado neste estudo, bem como as estratégias de leitura com o objetivo de situar o leitor quanto ao referencial teórico aqui assumido.

\section{Método}

Esta seção descreve o percurso da pesquisa realizada, isto é, a definição do tipo de pesquisa, os objetivos, hipóteses, escolha dos participantes, escolas participantes, instrumentos, situação de aplicação e critérios para correção das respostas do pré e do pós-teste, a aplicação e análise dos resultados do pré e do pós-teste.

A pesquisa foi do tipo colaborativa e comparativa, pois confrontou os resultados antes e pós-intervenção. Em se tratando de compreensão leitora procurou-se modificar o quadro encontrado, isto é, minimizar as dificuldades relatadas pelos estudantes por meio de um programa de ensino de leitura e de aplicação de estratégias metacognitivas.

Os objetivos gerais desta pesquisa foram: (a) investigar o alfabetismo funcional ao término do ensino fundamental brasileiro e (b) quais ações poderiam promover uma alteração no quadro descrito pelo PISA (2000) em contexto brasileiro e os objetivos especificos foram (1) avaliar habilidades de leitura que são necessárias para além do contexto escolar, (2) relacionar este desempenho em leitura com políticas públicas que visem reverter o baixo índice atual (PISA, INAF5), (3) permitir o monitoramento regular dos padrões de desempenho dos sujeitos que completam o ensino fundamental, (4) apresentar e aplicar técnicas e estratégias de leitura, para criar autoconsciência no leitor para que sejam instruídos na supervisão e monitoria de suas habilidades, buscando um melhor desempenho em leitura.

Para a primeira etapa, definição dos participantes e instrumentos, partiu-se do nome da escola disponibilizado pelo Ministerio da Educação no Brasil em que o PISA (2000, ciclo leitura) foi aplicado em Florianópolis, SC. Dos 50 alunos matriculados na oitava série (turma 81 e turma 82, T81 e T82, doravante), somente 12 estudantes foram considerados para esta pesquisa, pois as variáveis idade, série e nível socieconômico foram controladas. Foi possível verificar que eram estudantes de classe econômica de até três salários mínimos e em ambas as turmas havia repetentes.

\subsection{Os instrumentos de pesquisa}

Para controlar as variáveis deste estudo foram elaborados quatro instrumentos de pesquisa: (1) questionário de identificação, (2) levantamento psicossociolingüístico, (3) pré-teste e (4) pós-teste.

Os dois primeiros instrumentos tinham como objetivo identificar a idade e o perfil psicossociolingüístico dos participantes (profissão e escolaridade dos pais e se era ou não aluno repetente). Os instrumentos (3) e (4) buscavam avaliar o desempenho dos participantes em tarefas de leitura e foram compostos a partir de textos que circulam em nossa sociedade: de duas revistas (Veja e Superinteressante), de um jornal (Diário Catarinense) e de um livro didático para a elaboração do pré-teste, para o pós-teste, ostexto foram retirados de um jornal (Diario Catarinense), das revistas Terra, 
Galileu e Veja bem como de dois livros didáticos. Foram privilegiados textos informativos, curtos e de complexidade temática compatível com a série.

O objetivo de cada questão definiu a complexidade e respectivo escore. O pré-teste (antes da intervenção) foi composto de 4 textos 24 questões, o pós-teste (aplicado pós-intervenção) compreende 6 textos e 31 questões. Embora os textos fossem informativos, houve variedade quanto ao gênero: publicitário, gráfico e hipertexto.

Para a elaboração do pré e do pós- teste, inspirado no PISA (2000), procurou-se organizar e distribuir as questões equitativamente em ambos os testes por nível (fácil, médio, difícil) e por subescala (recuperação de informação, interpretação e reflexão), bem como por tipo de questão (escolha múltipla ou aberta), com vistas a avaliar os participantes quanto aos níveis de proficiência e subescalas (recuperação de informação, interpretação e reflexão), bem como por tipo de questão (escolha múltipla ou aberta).

\subsubsection{As subescalas e níveis do PISA (2000)}

Estão abaixo arrolados as subescalas e níveis inspirados no PISA (ciclo leitura). A primeira subescala compreende a localização e recuperação de informação, a segunda subescala se refere à interpretação de informações e finalmente a subescala reflexão. Os níveis fácil, médio e difícil permitem um escalonamento (dentro do parâmetro proposto para este estudo) para as questões. Casando subescala e nível é possível obter as seguintes descrições:

1) Subescala: Localização e recuperação de informação

Nível 1 (fácil): localizar uma ou mais informações explícitas em um texto, podendo haver informações concorrendo com a informação requerida;

Nível 2 (médio): reconhecer uma ou mais informações em um texto, podendo ser necessário fazer inferências básicas e a consideração de diversas condições;

Nível 3 (difícil): localizar a informação e, em alguns casos, reconhecer relações entre diversas partes de informação;

2) Subescala: Interpretação

Nível 1 (fácil): reconhecer o tema principal ou a proposta do autor, fazendo inferências básicas e podendo haver informações competindo com a requerida;

Nível 2 (médio): reconhecer a idéia principal de um texto (às vezes não se apresenta de maneira explícita), entendendo relações e construindo significados, e fazendo inferências básicas;

Nível 3 (difícil): integrar e ordenar várias partes de um texto para identificar a idéia principal, através de atividades que exigem um nível inferencial alto. As informações requeridas não se apresentam de maneira explícita;

\section{3) Subescala: Reflexão}

Nível 1 (fácil): relacionar a informação de um texto de uso cotidiano com outras

informações conhecidas;

Nível 2 (médio): compreender relações, construir sentido entre o texto e outros

conhecimentos da experiência pessoal;

Nível 3 (difícil): fazer conexões, comparações, dar explicações, ou até mesmo, avaliar características das informações referentes à forma de um texto.

\subsubsection{Estrutura do pré-teste}

O pré-teste é composto de 1 texto da revista Veja, 1 texto de jornal (Diário Catarinense), 1 propaganda de desodorante extraída da revista Superinteressante e 1 texto de livro didático. São 24 questões distribuídas por nível e por subescala. As questões ora são de múltipla escolha ora são questões abertas. Para recuperação temos um total de 12 questões; para interpretação somam-se 10 questões seguidas de 2 questões para reflexão. Ratifica-se o já exposto quanto a garantir que o pré- 
teste mostre qual é o mínimo esperado no desempenho de leitura. A partir dos níveis de proficiência, encontramos o total de 8 questões para fácil, para o nível médio 12 questões e finalmente para o nível difícil apenas 4 questões. O pré-teste procurou contemplar questões de nível mais fácil e médio, bem como procurou equilibrar as duas primeiras subescalas (recuperação e interpretação), pois a diferença entre ambas é de apenas 2 questões.

\subsubsection{A estrutura do pós-teste}

O pós-teste é composto de 31 questões que estão distribúídas em níveis de proficiência e subescala. O conjunto de questões foi elaborado pensando em avaliar os participantes, com vistas a revelar áreas de dificuldade em leitura: recupera informação, consegue interpretá-la, reflete sobre o que leu. Para compor os escores, levaram-se em conta a subescala e o nível de cada questão.

Procurou-se elaborar uma media de 10 questões por subescalas e por níveis diferentes para manter um balanceamento no teste. Assim, o pósteste revelou um percentual de 29\% para o nível fácil; para o nível médio 55\% e para o nível difícil, $16 \%$. Privilegiou-se o nível de questões médio, pois havia a expectativa de que os participantes pudessem atingir um melhor nível de desempenho em leitura pósintervenção participativa. As questões encontram-se divididas percentualmente por subescala: recuperação de informação $(29,03 \%)$, interpretação (39\%) e reflexão (32,2\%). Do total de 9,17 e 5 questões, respectivamente das subescalas mencionadas, a porcentagem correspondente a cada nível é de 29,03\% para nível fácil, 55\% para nível médio e finalmente $16 \%$ para nível difícil.

Após a finalização do pré-teste e do pós-teste, por questões metodológicas, foi realizado um teste piloto com uma turma com as mesmas variáveis controladas para o estudo em questão. O objetivo era aplicar o instrumento de avaliação (pré-teste), verificando a adequação de tempo, testando procedimentos escolhidos e repassando, quando da correção dos testes, os escores das questões. Para detalhamento, vide Dania (2007).

\subsection{Segunda etapa: os instrumentos de pesquisa aplicados ao grupo experimento}

Os instrumentos (1), (2) e (3) foram aplicados na primeira semana do mês de agosto (2005) em aulas cedidas pelo professores das turmas; após a intervenção participativa (de agosto a novembro) foi aplicado o pós-teste (início de dezembro) com tempo estimado de noventa minutos para realização, com organização de carteiras na sala, leitura das instruções para execução da tarefa e com o tempo informado. Cada estudante recebeu um conjunto impresso para uso individual dos textos e perguntas que compuseram ambos o pré e pós teste.

Os resultados dos instrumentos (1) e mostraram que havia 50 estudantes matriculados, somente 12 estavam com idade media entre 14,7 anos e não eram repetentes; havia grande concentração de familias com renda de até dois salários mínimos. Os pais ocupavam funções que demandam poucas habilidades de leitura e de escrita: pedreiros, marceneiros, pintores, mecânicos e autônomos; as mães, diaristas, domésticas ou não trabalham fora de casa. Os estudantes ouviam diferentes gêneros de música: hip-hop (65\%), funk $(20 \%)$ e outros (15\%). Assistiam tv, rede Globo (90\%) e outros (10\%) e afirmaram não gostar de ler (85\%). Consideravam-se bons leitores (30\%, T81; 55\% na T82).

Os resultados do pré-teste mostraram escores baixos em ambas as turmas investigadas. Houve concentração de escores abaixo de 4,0. Na turma 81, 1 participante estava entre 1,0 a 2,0; dois participantes estavam entre 2,1 a 3,0 seguidos também de dois participantes entre 3,1 a 4,0. Somente um participante estava entre 4,1 a 5,0. A situação não foi muito diferente na turma 82: dois participantes com escore entre 1,0 a 2,0; três participantes com escores entre 2,1 a 3,0 e outros três participantes entre 3,1 a 4,0. Nesta turma não obtivemos participantes com escores acima de 4,1. 
Os participantes que realizaram o pré-teste obtiverem escores baixos para o parâmetro entre 0,0 e 10,0. A média aritmética foi de 3,0 e 2,37 respectivamente para as turmas 81 e 82 . Isto é igual a dizer que os sujeitos decodificavam o que leram, mas fizeram uma leitura muito superficial do texto. As questões que obtiveram mais acertos foram aquelas de subescala recuperação de informação e de nível fácil.

\subsection{A intervenção colaborativa}

Com base nos instrumentos de pesquisa (1), (2) e (3), foi elaborada uma intervenção participativa que pudesse provocar engajamento dos professores e qualitativamente significativo (ensino de estratégias de leitura) por meios das disciplinas de ciências, matemática, geografia e historia que foram o corpus de investigação deste estudo, com vistas a melhorar o desempenho em leitura dos participantes investigados. Justifica-se a sua escolha levando em conta o número de textos escritos que circulam nas disciplinas arroladas.

Com base em observação de aulas, os professores foram orientados a explorar os elementos dos textos, com foco na pré-leitura (títulos, gravuras, autor, ano de publicação etc). A partir da compreensão da importância desta etapa, passou-se a trabalhar com a ativação do conhecimento prévio, recorrendo às aulas anteriores, ao conhecimento do aluno sobre o tema. Visava-se ativar o esquema que permitisse uma melhor abordagem da leitura por meio das seguintes orientações: (1) ativação do conhecimento prévio e valorização das contribuições espontâneas dos alunos, (2) levantamento de hipóteses, (3) formulação de objetivos, (4) leitura silenciosa, (5) monitoramento de compreensão da leitura, através de detectar problemas de vocabulário e procurar resolvê-los via pistas textuais, (6) respostas a exercícios orais ou escritos, buscando uma compreensão total ou parcial do texto.

Os planos de aula foram reorganizados com vistas a promover e aplicar as estratégias metacognitivas por meio das seguintes ações: (1) ativar conhecimento prévio, (2) levantar hipóteses, (3) traçar objetivos, (4) ler o texto e reler partes, quando necessário, (5) sublinhar ou destacar as partes mais importantes de cada parágrafo, (6) monitorar a compreensão, detectando problemas e resolvendoos, (7) releitura, (8) exercícios orais ou escritos de compreensão e (9) registro escrito das respostas ou resumo do que foi estudado.

O extrato a seguir ilustra uma prática em leitura realizada no período de intervenção deste estudo e ocorreu em uma aula de história. A professora solicitou aos estudantes que respondessem as seguintes perguntas que foram escritas no quadro. Trata-se de texto sobre o tema " Segunda Guerra Mundial":

1. De que forma a primeira guerra mundial contribuiu para que se deflagrasse a

segunda? Justifique sua resposta.

2. Qual país lançou as bombas atômicas no Japão e qual foi o impacto mundial deste ato, na sua opinião?

3. A perseguição aos judeus e outras minorias foi considerado um dos horrores do século. Explique o que aconteceu nos campos de concentração. Qual é sua opinião sobre os campos de concentração?

4. Pode-se dizer que este tipo de perseguição terminou com o fim da Segunda Guerra? Há populações vítimas de preconceitos no Brasil em 2005? Justifique sua resposta.

5. Como terminou a segunda guerra mundial?

6. Na sua opinião, a guerra e a violência podem ser usadas para resolver conflitos?

Após a fase de respostas individuais, teve início a comparação de respostas com o colega, seguida de correção coletiva. Ao dar início à correção, a professora disse o número da pergunta que estava escrita no quadro e chamou uma dupla para responder. Encaminhou a resposta para o grande grupo, perguntando se todos concordavam. Em caso de dúvida, ou discordância, a professora retomou o texto e procurou induzir a resposta certa. $\mathrm{A}$ resposta considerada adequada pela professora e 
pelo grupo foi escrita no quadro e comparada com àquelas previamente elaboradas pelos alunos.

\subsection{Quarta etapa: a aplicação do pós-teste ao grupo experimental}

A aplicação do pós-teste ocorreu na primeira semana de dezembro em situação controlada já descrita. Os resultados quantitativos mostraram que a diferença na média aritmética entre as duas oitavas séries foi de 0,5 . Houve variabilidade nos escores para o parâmetro de 0,0 a 10 . Para a turma 81 os escores estavam entre 2,3 a 6,1 e para a turma 82 os escores estavam entre 1,6 a 6,75.

Observou-se que houve variedade na distribuição de escores dentro do parâmetro entre 0,0 e 10: concentração de participantes para escores entre 2,1 a 3 (3 participantes), bem como para escores entre 6,1 a 7,0 (3 participantes), seguidos de 2 participantes para escores entre 4,1 a 5,0 e outros 2 participantes para escores entre 5,1 a 6,0. Houve 1 participante para escores entre 1,0 a 2,0 e 1 participante para escores entre 3,1 a 4,0.

Os resultados quantitativos do pós-teste mostraram que houve variabilidade nos escores: $8,3 \%$ para notas 1,0 a 2,0; $25 \%$ para notas entre 2,1 e 3,$0 ; 8,3 \%$ para notas entre 3,1 e 4,$0 ; 16,6 \%$ para notas entre 4,1 e 5,0 , 16,6\% para notas entre 5,1 e 6,0 e $25 \%$ dos alunos com notas entre 6,1 e 7,0, dentro do parâmetro de 0,0 a 10 . Não houve notas acima de 7,0. A média aritmética do pós-teste foi de 4,25 para ambas as turmas. Os escores foram baixos dentro do parâmetro de 0,0 a 10 . Não houve escores acima de 5,0. A diferença da média aritmética entre ambas as turmas foi de 0,5. Houve uma grande variação na notas e que vão de 2,3 a 6,1 na turma 81 e de 1,6 a 6,75 na turma 82 . Atentando para a distribuição das notas, observou-se que além da variação, encontramos 5 participantes acima de 5,0 , nota de aprovação na escola, os restantes (7 participantes) não teriam sido aprovados.

\section{Análise e discussão dos resultados}

Os resultados coletados pela pesquisa permitiram realizar análise quantitativa, qualitativa e estatística procurando quantificar, explicar e verificar se houve diferença entre os resultados do pré-teste e do pós-teste.

\subsection{Análise quantitativa}

Para analisar os dados quantitativos do pósteste, foram elaborados os seguintes agrupamentos: o demonstrativo de acertos e erros por questão, o percentual de acertos por subescalas bem como o demonstrativo de questões em que houve maior número de acertos e de erros.

Para totalizar a quantidade de acertos, erros e brancos foram somados os números de cada questão por turma, procedimento repetido ao longo da análise. O máximo de acertos por questão é 12, pois este é o número de participantes que realizou o pós-teste. Assim, foi possível afirmar que a questão 5 do texto 01 totalizou 08 acertos. No texto 03, a questão 01 apresentou 08 acertos, bem como a questão 03 do mesmo texto. A questão 07 do texto 03 foi aquela que somou 10 acertos. Já no texto 04 encontramos 10 acertos para a questão 01. No texto 06, obtivemos 09 acertos para a questão 01 e 08 acertos para a questão 02. A questão 04 do texto 01 junto com a questão 02 do texto 02 foram as que obtiveram 0 maior número de erros (10) de todo o teste, seguidas das questões 03 do texto 01 e da questão 1 do texto 02: ambas com 08 erros cada. Finalmente com 06 erros encontram-se as questões 06 do texto 01 e 06 do texto 03. O quadro a seguir ilustra a distribuição descrita: 
Quadro 1: Demonstrativo de acertos, erros e brancos por turma

\begin{tabular}{|c|c|c|c|c|c|c|}
\hline \multirow[b]{2}{*}{ Texto 1} & \multicolumn{2}{|l|}{ Acertos } & \multirow{2}{*}{$\begin{array}{c}\text { Erros } \\
\text { T81 }\end{array}$} & \multicolumn{3}{|c|}{ Brancos } \\
\hline & T81 & T82 & & T82 & T81 & T82 \\
\hline Qvestão 1 & 3 & 4 & 3 & 2 & 0 & 0 \\
\hline Questão 2 & 2 & 3 & 3 & 2 & 1 & 1 \\
\hline Qvestão 3 & 2 & 2 & 4 & 4 & 0 & 0 \\
\hline Qvestão 4 & 1 & 1 & 5 & 5 & & \\
\hline Questão 5 & 5 & 3 & 1 & 3 & 0 & 0 \\
\hline $\begin{array}{l}\text { Qvestão 6 } \\
\text { Texto 2 }\end{array}$ & 3 & 1 & 2 & 4 & 1 & 1 \\
\hline Qvestão 1 & 1 & 1 & 5 & 3 & 0 & 2 \\
\hline Qvestão 2 & 0 & 0 & 6 & 4 & 0 & 2 \\
\hline Qvestão 3 & 4 & 3 & 2 & 2 & 0 & 1 \\
\hline Qvestão 4 & 1 & 1 & 3 & 3 & 4 & 0 \\
\hline Questão 5 & 4 & 2 & 2 & 0 & 4 & \\
\hline \multicolumn{7}{|l|}{ Texto 3} \\
\hline Qvestão 1 & 2 & 6 & 4 & 0 & 0 & 0 \\
\hline Questão 2 & 3 & 1 & 2 & 2 & 1 & 3 \\
\hline Questão 3 & 5 & 3 & 1 & 1 & 0 & 2 \\
\hline Qvestão 4 & 4 & 3 & 3 & 0 & 2 & 0 \\
\hline Questão 5 & 3 & 3 & 1 & 1 & 2 & 2 \\
\hline Qvestão 6 & 4 & 0 & 2 & 4 & 0 & 2 \\
\hline Questão 7 & 5 & 5 & 0 & 0 & 1 & 1 \\
\hline \multicolumn{7}{|l|}{ Texto 4} \\
\hline Qvestão 1 & 5 & 5 & 1 & 1 & 0 & 0 \\
\hline Qvestão 2 & 4 & 4 & 1 & 1 & 1 & 1 \\
\hline Qvestão 3 & 2 & 2 & 2 & 2 & 2 & 2 \\
\hline Qvestão 4 & 2 & 3 & 3 & 0 & 1 & 3 \\
\hline \multicolumn{7}{|l|}{ Texto 5} \\
\hline Qvestão 1 & 4 & 4 & 1 & 1 & 1 & 1 \\
\hline Qvestão 2 & 1 & 2 & 3 & 3 & 2 & 1 \\
\hline Qvestão 3 & 4 & 3 & 1 & 1 & 1 & 2 \\
\hline Qvestão 4 & 1 & 1 & 3 & 3 & 2 & 2 \\
\hline Qvestão 5 & 0 & 2 & 3 & 2 & 3 & 2 \\
\hline \multicolumn{7}{|l|}{ Texto 6} \\
\hline Questão 1 & 5 & 4 & 0 & 1 & 1 & 1 \\
\hline Qvestão 2 & 5 & 3 & 0 & 1 & 1 & 2 \\
\hline Qvestão 3 & 0 & 0 & 3 & 3 & 3 & 3 \\
\hline Qvestão 4 & 2 & 0 & 2 & 3 & 2 & 3 \\
\hline
\end{tabular}

Com base na distribuição do número de acertos por níveis, na distribuição do número de acertos por subescalas e no percentural de acertos por níveis e subescalas, foi possível afirmar que houve um maior número de acertos para as questões de nível médio; houve 28 e 20 acertos para as questões de nível fácil; 47 e 46 acertos para as questões de nível médio e 13 e 09 acertos para as questões de nível difícil.

Para 12 participantes investigados o número máximo de acertos por subescalas é 108 para recuperação; 144 para interpretação, seguido de 120 para reflexão, totalizando 252 acertos para 31 questões. Encontram-se assim distribuídos por subescalas e por turma (81 e 82, respectivamente): 28 e 21 acertos para reflexão, 39 e 27 acertos para interpretação seguidos de 21 e 26 questões para reflexão. $O$ total de acertos para a turma 81 é de 88 e para a turma 82 é de 74. Percentualmente, as questões respondem por $29 \%$ para a subescala recuperação, 39\% para a subescala interpretação e
$32 \%$ para a subescala reflexão conforme o quadro a seguir:

Quadro 2: Distribuição do número de acertos por subescalas.

\begin{tabular}{lccccc|}
\hline Subescalas & T81 & T82 & Total questões Total max.acertos & $\%$ \\
Recuperação & 28 & 21 & 9 & 108 & 29 \\
Interpretação & 39 & 27 & 12 & 144 & 39 \\
Reflexão & 21 & 26 & 10 & 120 & 32 \\
Total & 88 & 74 & 31 & 252 & 100 \\
& & & & \\
& \\
& O nível médio foi o que obteve maior índice de
\end{tabular}
acerto (204) e com 55\%, seguido do nível fácil (108), com 29\%. As questões de nível difícil obtiveram 60 acertos (16\%) do total. Por subescala as questões de interpretação obtiveram 144 acertos, seguidas de 120 para reflexão e 108 de recuperação de informação.

Estes números foram obtidos por meio do cruzamento do total de questões (31) com o número de acertos máximo (372) para os participantes que realizaram esta tarefa (12). Assim, foram feitos os cálculos percentuais levando em conta os níveis e subescalas das questões. Foi possível afirmar que referente às subescalas, as que apresentaram maior número de acertos foram a interpretação e a de nível médio. Observou-se que uma subescala como esta, considerada mais complexa, tenha apresentado um número de acertos maior, se comparada às outras do teste. Verificou-se que a subescala recuperação ficou em segundo lugar seguida da subescala reflexão, considerada a mais difícil.

Considerando as 31 questões que compõem o teste, foi possível afirmar que houve uma preocupação em dividir as questões por níveis e subescalas, conforme já mencionado. Observou-se, porém, que a subescala interpretação foi responsável por um número maior de questões (12), se comparada a subescala recuperação (9) ou a subescala reflexão (10 questões). Isto talvez possa explicar por que as subescalas que apresentam maior número de questões poderiam ter maior número de acertos.

Os resultados quantitativos do pós-teste mostraram que houve variabilidade nos escores: $8,3 \%$ para notas 1,0 a 2,$0 ; 25 \%$ para notas entre 2,1 e 3,$0 ; 8,3 \%$ para notas entre 3,1 e 4,$0 ; 16,6 \%$ para notas entre 4,1 e 5,0,16,6\% para notas entre 5,1 e 
6,0 e $25 \%$ dos alunos com notas entre 6,1 e 7,0, dentro do parâmetro de 0,0 a 10 . Não houve notas acima de 7,0. A média aritmética do pós-teste foi de 4,25. Os dados revelaram que houve um grande número de acertos para as questões consideradas mais fáceis (recuperar e interpretar informação) e um número reduzido de acertos para as questões consideradas mais difíceis (estabelecer relações entre as informações e refletir sobre elas).

\subsection{Análise estatística}

A análise estatística compara as diferenças encontradas entre o pré e o pós-teste. Esta análise permitiu afirmar se a diferença é significativa ou não, dentro de limites e procedimentos escolhidos. A média dos testes, o desvio padrão e o Teste $t$ pareado foram ferramentas utilizadas para a análise dos dados.

$\mathrm{O}$ Teste $t$ pareado mostra que o que se divide é diferença entre as duas médias que se deseja comparar pelo desvio padrão comum às amostras a que elas se referem. $O$ valor resultante indica quantas vezes a distância que vai de uma média à outra contém a distância representada pelo desvio padrão. É preciso levar em conta que podem ocorrer erros do Tipo I, resultados são significativamente diferentes, quando na verdade não o são, ou do Tipo II, dá um resultado não significativo.

Com base nos cálculos estatísticos do Teste $t$ para amostras emparelhadas, foi possível afirmar que o pré-teste teve resultado diferente do pós-teste (margem de erro $0,7 \%$ ao se fazer esta afirmação). A diferença das médias entre as duas variáveis analisadas foi de 1,6 com desvio padrão de 1,7. Foram também encontrados os desvios padrão $1.1 \mathrm{e}$ 1.8 para pré-teste e pós-teste respectivamente.

Também foram feitas comparações, baseadas nos dados acima, da média e desvio padrão por turma (B-A), isto é, diferença entre pós-teste e préteste: encontrou-se para a T81 a média de $1.43 \mathrm{com}$ desvio padrão de 0.68; para a T82 foi encontrada a média de 1.81 com desvio padrão de 2.33. As médias mostraram um desempenho melhor da turma da T82, mas o desvio padrão encontrado nesta turma foi muito superior ao da T81. Isto se deveu ao participante 12 que obteve 5.2 na diferença pré-teste e pós-teste, razão da elevação da média e do desvio padrão.

Observou-se que houve uma distribuição bem heterogênea das diferenças pós versus pré-teste. 1.0 foi considerado, para efeito desta pesquisa, diferença significativamente importante. $\mathrm{Na}$ T81, em ordem crescente encontramos os seguintes resultados: 0.7, $0.8,1.1 ., 1.6,2.0$ e 2.4. As diferenças encontradas foram todas positivas. Desta forma 4 participantes (S4, S6, S3 e S5) foram considerados com diferenças significativamente importantes. Na T82, houve muita variação nas diferenças encontradas: $-1.0,-0.1,1.3$, 1.7, 3.8 e 5.2. Os participantes S7, S8, S11 e S12 apresentaram diferenças positivas: $1.3,3.8,1.7$ e 5.2 respectivamente. Os participantes $S 9(-0,1)$ e $S 10$ (1,0) não apresentaram diferença positiva na comparação pré-teste versus pós-teste.

Foi possível, com base na distribuição descrita acima, afirmar que que 7 participantes alcançaram diferença de até 2.0 pontos $(58 \%) ; 3$ participantes alcançaram diferença acima de 2.0 (25\%) e 2 participantes não obtiveram diferença positiva: até 1.0 (16,6\%). Esta distribuição permitiu observar que houve concentração de diferença entre 1.0 a 2.0 (5 participantes: S4, S6, S7, S11 e S3). Acima de 2.0 de diferença encontramos S5, S8 e S12 com respectivamente 2.4, 3.8 e 5.2. Foram encontradas as diferenças negativas para os participantes S9 (-0.1) e S10 (-1.0) e positivas, abaixo de 1.0, para os participantes S1 (0.7) e S2 (0.8).

No Teste $t$ pareado foram empregados $n-1$ graus de liberdade, ou seja, 11. Como o intervalo de confiança $(0,6 ; 2,7)$ exclui o zero, rejeita-se a hipótese nula que diz que a diferença das médias é zero a um nível de significância de 5\%. Reforça-se esta afirmação pela análise do p-valor $(0,006900826)$ que resultou em um valor inferior a 0,05. Com base no exposto, a explicação para os resultados encontrados se deveu a um motivo que é a causa da diferença encontrada entre os grupos: a intervenção participativa. 


\subsection{Análise qualitativa}

Quanto ao pós-teste, consideramos ter havido uma correlação entre acertos e erros e o grau de dificuldade das questões. O parâmetro de definição do grau de dificuldade das questões (nível fácil, médio e difícil) encontra respaldo no teste piloto (testagem realizada com outra turma de perfil igual ao grupo experiemental realizada para promover ajustes nos testes e nos procedimentos de aplicação na turma investigada), isto é, uma questão que apresenta maior número de acertos deveria ser considerada fácil e conseqüentemente de um nível mais baixo do que uma questão que obteve um baixo índice de acertos.

Assim, pode-se afirmar que questões de nível mais fácil e médio obtiveram mais acertos do que as questões de nível difícil. O mesmo se aplicou às subescalas, pois uma questão que recupera informação pode ser considerada menos complexa e apresentar mais acertos, se comparada a uma questão de subescala de reflexão.

A análise quantitativa mostrou a quantidade de acertos, erros e de brancos por questão e tentou explicar os dados encontrados. Por exemplo, o texto extraído de um jornal que aborda a saúde infantil e procura valorizar os elementos que a promovem: boa alimentação, acompanhamento médico, amamentação, a função dos agentes públicos de saúde e perguntava sobre o tema do texto e foram oferecidas quatro alternativas de escolha. O objetivo da questão era integrar partes do texto de modo a verificar uma ideia central, entender uma relação ou construir significado. Observou-se que esta questão, embora facilitada pelas alternativas da múltipla escolha, obteve 07 acertos. Os participantes tiveram dificuldade de integrar partes e verificar qual das alternativas corresponderia à idéia central que melhor descrevia o assunto do texto. Foram encontradas 03 respostas para a alternativa (b), demonstrando dificuldade em decidir pela idéia geral, usando a estratégia de emparelhar o adjetivo "infantil" com o que apareceu no texto. Foram encontradas 02 respostas em branco que reforçam a dificuldade de verificação de uma idéia central de um texto (vide Dania, 2007 para maior detalhamento).

Foi possível ainda observar, através da análise quantitativa e qualitativa das questões propostas para o pós-teste, que as questões que obtiveram maior número de acertos foram as de subescala de recuperação e as de interpretação de nível fácil e médio. Observou-se que o nível e a subescala interferem no número de acertos, pois isto foi recorrente nas demais questões.

Embora os resultados mostrem que os participantes tiveram maior facilidade com questões mais fáceis e maior dificuldade em questões mais complexas, observou-se que houve uma moderada melhora no desempenho de leitura dos alunos pesquisados, apesar das notas baixas.

Os resultados revelam também que a familiaridade com o tema e o gênero (reportagem) do texto foi fator decisivo para o acerto das questões, como foi verificado no tema abordado pela revista Veja que versava sobre troca de sexo na adolescência. Por outro lado, nenhuma das questões abertas chegou a obter 10 respostas corretas: a dificuldade em argumentar foi flagrante e a leitura de gráficos esbarrou com enormes dificuldades.

\section{Discussão geral dos resultados}

Os dados levantados pelos instrumentos de pesquisa citados mostraram que os participantes investigados estão em nível de escolaridade superior a de seus pais, poucas atividades de leitura são realizadas fora da escola e que os participantes se declararam como leitores bons ou regulares. Isto não se comprovou em tarefas de leitura realizadas em contexto escolar. Ao contrário, corrobora os dados divulgados pelo PISA (2000): os alunos que concluem o ensino fundamental não conseguem avançar para níveis mais complexos de leitura: interpretar e fazer inferências. Sem compreender e interpretar não podem ser críticos de forma consistente.

Decorre do exposto a conivência dos professores para manter uma prática pedagógica que em nada contribuiu, contribui ou contribuirá para que 
possamos melhorar o quadro atual. É da formação teórica e metodológica do professor que depende 0 ensino da leitura ao longo da escolaridade.

Foi neste cenário que se buscou verificar se - ensino de estratégias metacognitivas poderia melhorar o quadro de desempenho em compreensão leitora descrito pelo PISA (2000). Assim, foi verificado e comparado o desempenho em leitura antes e após a intervenção por meio de textos que circulam socialmente, ancorado no conceito de letramento aqui defendido.

Observou-se durante a etapa de observação das aulas e também da etapa de intervenção colaborativa que os estudantes não tem o hábito de retomar o texto para buscar informações específicas ou percorrer diferentes partes do texto em busca de uma informação ou de uma relação entre partes. Procurou-se enfatizar a pré-leitura e o ensino de estratégias metacognitivas que muito auxiliaram na melhora de desempenho como se verificou na comparação pré versus pós-teste.

Pelo que foi exposto, confirma-se também a importância dos esquemas como necessários para a compreensão de textos escritos. Cabe à escola "ampliar e aprofundar tais esquemas ou universos, o que ocorre, principalmente, através da leitura". (SCLIAR-CABRAL, 2003b, p.35).

Tanto a análise quantitativa quanto a qualitativa mostraram que os alunos acertaram questões mais fáceis e tiveram dificuldade com questões mais complexas. Observou-se uma modesta melhora no desempenho de leitura, tomando como referência o pré-teste. Desta forma, após a intervenção colaborativa, aponta-se para a veracidade da hipótese alternativa desta pesquisa que diz que alunos submetidos a um programa de desenvolvimento de estratégias metacognitivas apresentam melhor desempenho em leitura.

Foi possível afirmar a importância dos esquemas como necessários para a compreensão dos textos escritos. Uma vez que os sujeitos têm poucas práticas de leitura, pode-se verificar que as práticas de escrita também, como decorrência, ficam comprometidas. Também foi flagrante a dificuldade de responder as questões abertas de forma argumentativa, o que mostra que estes sujeitos apresentam dificuldades para construir ideias e fazer julgamentos.

Os dados empíricos possibilitam identificar áreas de dificuldade no processamento de leitura, confirmando o modelo adotado. A escolha do PISA como suporte para os testes de desempenho em leitura possibilitou construir uma proposta de avaliação em leitura que buscou detectar níveis e subescalas de leitura. Foi possível verificar, através dos dados, localizar áreas de dificuldade. Confirmouse a necessidade de praticar a leitura e a escrita em atividades cotidianas de sala de aula, uma vez que a análise qualitativa mostrou dificuldades relacionadas ao raciocínio, ao compreender e interpretar informações escritas tanto em prosa quanto em forma esquemática.

\section{Considerações finais}

$\mathrm{Na}$ primeira etapa desta investigação foram construídos os instrumentos e definidos os participantes; na segunda etapa os instrumentos foram aplicados à população experimental. Os resultados do pré-teste mostraram que os sujeitos tem dificulades em tarefas em leitura. Seguiu-se a etapa de intervenção que permitiu, com base na observação das aulas, uma reestruturação dos planos de aula, visando ensinar estatégias metacognitivas de leitura. Finalmente, na quarta etapa, foi aplicado o pós-teste e realizadas as análises quantitativa, qualitativa e estatística dos dados para posterior confirmação da hipótese de pesquisa.

Foi possível afirmar que o desempenho em leitura é muito baixo, mesmo após o período de intervenção colaborativa, ficando aquém do esperado para sujeitos que completam oito anos de escolaridade formal. Este dado indica uma dificuldade em leitura e corrobora os dados do PISA e INAF já mencionados. Somente uma intervenção colaborativa não resolve o problema do analfabetismo funcional, embora tenha sido possível constatar uma melhora de desempenho em leitura na população investigada. 
Também é preciso destacar que os estudantes que completam o ensino fundamental estão em condições de letramento abaixo da esperada, tomando como critério os anos de estudo. No caso desta pesquisa, ficou evidente que existem níveis de desempenho e, desta forma reforça-se o continuum do letramento.

Pelo que foi exposto, não adianta somente matricular as pessoas na escola. É preciso investir no ensino. Pode-se traduzir este investimento por melhor fundamentação teórica e metodológica dos professores, tanto da rede privada como da rede pública. A necessidade da formação continuada dos professores também precisa ser incentivada. Para os alunos, é preciso garantir o acesso à cultura letrada. Não basta ler. Há que se desenvolver como se lê. Uma leitura apressada ou superficial não é de muita ajuda.

Pode-se afirmar que os objetivos traçados para esta pesquisa foram atingidos, devidamente ancorados pela literatura e obedecendo à metodologia estabelecida para os fins propostos por esta investigação. Os resultados do pós-teste podem ser considerados satisfatórios, levando-se em conta o contexto de práticas de leitura e escrita da população experimental.

O artigo procurou revisitar o tema leitura, processamento em leitura e estratégias metacognitivas e ensino buscando descrever pesquisa realizada em 2005. Os dados, embora modestos, encontrados pelo estudo permitem afirmar que houve mudança na compreensão leitora dos sujeitos investigados. Foi possível, por meio dos instrumentos de pesquisa, explicar a natureza das dificuldades encontradas e a análise estatistica possibilitou afirmar que a diferença encontrada entre pré e pós-teste se deveu à intervenção colaborativa. Desta forma, aceitou-se a hipótese alternativa desta pesquisa. Observou-se que 0 uso de estratégias metacognitivas, aplicadas ao contexto investigado, promoveu uma melhorar relativa no desempenho em leitura.

Revisitar os temas propostos pelo artigo contribui para um reflexão crítica sobre a leitura e o ensino da leitura em contexto escolar brasileiro. Não tem havido mudanças significativas dos padrões de desempenho encontrados desde as primeiras avaliações do PISA (2000, ciclo leitura). O Brasil tem alçançado desempenho pífio nas avaliações realizadas nos últimos anos também em ciências e em matemática.

No caso específico do analfabetismo funcional, em contexto brasileiro, as políticas de intervenção devem integrar 0 processo de aprendizagem e desenvolvimento das habilidades de leitura e de escrita, possibilitando estabelecer nexos entre a educação fundamental e a educação continuada. É uma proposta que se inicia com a alfabetização na perspectiva do letramento e com o acesso à informação. O letramento, portanto, é um traço comum a várias atividades que caracterizam as sociedades contemporâneas: a escola, o trabalho, a religião, a política.

Finalmente, os dados empíricos desta pesquisa não podem ser tomados como generalização de causas do analfabetismo funcional e nem a intervenção realizada como única solução para enfrentar o problema. Espera-se que este estudo possa servir como reflexão sobre o letramento, o analfabetismo funcional (a complexidade do fenômeno) sobre propostas que revisitem e modifiquem a formação dos professores (mal preparados), os currículos (privilegiando os mesmos conteúdos) e o material didático (de qualidade questionável) que combinados têm perpertuado uma prática pedagógica que nada tem contríbuído para o desenvolvimento e o domínio da leitura ao longo da escolaridade.

\section{Referencias}

BAKER, L.; BROWN, A. Cognitive monitoring in reading. IN; FLOOD, J.(Org.) Understanding reading comprehension: cognition, language and the structure of prose. Newark, Delaware: IRA., 1984.

BROWN, A. Metacognitive skills and Reading. In: PEARSON, D. (Org.). Handbook of reading research. New York: Logman, 1980. p.353-394. 
DANIA, R.C. "Professora, eu não sei ler!": Uma contribuição para minimizar a produção de analfabetos funcionais. Universidade Federal de Santa Catarina, Programa de Pós-Graduação em Linguística. Tese, 2007.

FAERCH, C; KASPER, G. Processes and strategies in foreign language learning and comunnication, 1980. In: FUJITA, M. et. al. Estratégias de Leitura. Disponível em http://www.prudent.unesp.br/dcartog/arlete/hparlet e/couseware/estrategias.htm>. Acesso em : 06 mai.2005.

GOODMAN, K. Reading; a psycholinguistic guessing game. In: H.Singer \& R.B. Ruddel (Org.). Theorical Models and Processes of Reading. Newark: International Reading Association, 1976, p. 497508.

GOUGH, P.B. One second of reading. In: H.Singer \& R.B. Ruddel (Org.). Theorical

Models and Processes of Reading. Newark: International Reading Association, 1976. p.509535.

INAF. 5ำ Indicador Nacional de Alfabetismo Funcional - Um diagnóstico para a

inclusão social pela educação (Avaliação de Leitura e Escrita). São Paulo: IBOPE/Instituto Paulo Montenegro/Ação Educativa, 2005. Disponível em

$<$ http://www.ipm.org.br/download/inaf05.pdf>. Acesso em: 09 set.2005.

KATO, M.A. No mundo da escrita: uma perspectiva psicolingüística . São Paulo: Ática, 1986.

LABERGE , D.; SAMUELS, S. Toward a theory of automatic information processing in reading. Cognitive Psychology. n.6, p.293-323, 1974.

MORAIS, J. A Arte de ler. São Paulo: Editora da Universidade Estadual Paulista, 1996.

MORAIS, J.; KOLINSKY, R. A Ciência cognitiva da leitura e a alfabetização. Pátio, São Paulo, n.29, p.14-17, 2004.
ORGANISATION FOR ECONOMIC COOPERATION AND DEVELOPMENT. Programme for International Student Assessment. Sample tasks from PISA 2000 assessment of reading, mathematical and scientific literacy. Paris: OECD Publications, 2002.

OXFORD, S. Language learning strategies: what every teacher should know, 1989. In: FUJITA et al., 2001. Disponível em <

http://www.prudent.unesp.br/dcartog/arlete/hparlete/c ouseware/estrategias.htm>. Acesso em : 06 mai.2005.

SCLIAR-CABRAL, L. Processos psicolingüísticos de leitura e a criança. Letras de Hoje, n.19, p.27-113, 1986.

Princípios do sistema alfabético do português do Brasil. São

Paulo: Contexto,2003 a.

Guia Prático de alfabetização, baseado em Princípios do sistema alfabético do português do Brasil. São Paulo: Contexto, 2003 b.

SOARES, M. Letramento: como definir, como avaliar, como medir. In: SOARES, M.

Letramento: um tema em três gêneros. Belo Horizonte: Autêntica, 1998, p.61-125.

Alfabetização e Letramento. São Paulo: Contexto, 2003.

\section{COMO CITAR ESSE ARTIGO}

DANIA, Rejane Croharé. Processamento em leitura, estratégias metacognitivas e ensino: revisitando os temas. Signo, Santa Cruz do Sul, v. 43, n. 77, p. 125-142, jul. 2018. ISSN 1982-2014. Disponível em: <https://online.unisc.br/seer/index.php/signo/article/view/12022>. Acesso em: http://dx.doi.org/10.17058/signo.v43i77.12022. 